\title{
The 2001 Educational Policy and Accreditation Standards: Issues and Opportunities for BSW Education
}

\author{
Irene Queiro-Tajalli \\ Katharine Byers \\ Edward Fitzgerald
}

\begin{abstract}
The Educational Policy and Accreditation Standards (EPAS) combines social work educational policies and accreditation standards within a single document. The EPAS establishes guidelines for baccalaureate and masters' level social work education throughout the United States. In this article, the authors discuss the implications of the EPAS for Bachelor of Social Work (BSW) programs. They focus especially upon those aspects of the EPAS that relate to foundation-level program objectives and curriculum content.
\end{abstract}

Keywords: BSW education, social work, EPAS, educational policies, accreditation standards

$\mathrm{T}$ The 2001 Educational Policy and Accreditation Standards (EPAS) integrates in a single document curriculum policies and accreditation standards and combines the mandates for social work education at the BSW and MSW levels. It is too early to say how well this document will serve social work educators and students. We can say, however, that the EPAS document is a reflection of efficiency-one of the elements of a McDonaldized society (Ritzer, 2000).

This article discusses the educational opportunities and concerns related to EPAS. In considering the implications of EPAS for BSW programs, we focus primarily upon the foundation program objectives and foundation curriculum content sections under the Educational Policy section. We also discuss selected passages in the Accreditation Standards section.

\section{EDUCATIONAL POLICY}

The Educational Policy sets the basis for the accreditation standards by defining the purposes of the social work profession and education, the structure of social work education, program objectives, and the foundation curriculum content.

The Educational Policy mandates baccalaureate social work programs to achieve 12 foundation program objectives. These objectives reflect the common

Irene Queiro-Tajalli, Ph.D. is Professor and Director of Undergraduate Education, Indiana University School of Social Work; Katharine Byers is Associate Professor and B.S.W. Program Director, Indiana University School of Social Work, Indiana University Bloomington Campus; and Edward Fitzgerald, M.S.W., J.D. is Assistant Professor and B.S.W. Program Director, Indiana University School of Social Work, Indiana University East campus. 
body of the profession's knowledge, values, and skills. A close look at both the 1992 and 2001 program objectives indicates that practically no differences exist between these two sets of objectives. While there are some differences in language, the intent of the objectives appears the same. Perhaps, the difference will be in the way programs link these objectives to their assessment plans to demonstrate objective achievement as required under the content area "Program Assessment and Continuous Improvement." The foundation curriculum, reflected in eight curriculum content areas and in conjunction with a liberal arts perspective, mandates coverage of professional knowledge, values, and skills to meet the foundation objectives. In the following pages we focus on selected aspects of the foundation curriculum.

\section{Values and Ethics}

Social work is a value-based profession (Gordon, 1965) that is subject to change (Congress, 1999). As a result, the curriculum in this area needs to be sufficiently open to accommodate to societal changes (e.g., advances in medicine and technology). This content area expects social work programs to "integrate content about values and ethical decision making as presented in the National Association of Social Workers Code of Ethics" (CSWE, 2001, p. 9) in their foundation curriculum and prepare students to "understand the value base of the profession and its ethical standards, and practice accordingly" (p. 8). These expectations seem to establish the NASW Code of Ethics (NASW, 1999) as the primary guide for ethical decision-making. This raises issues and opportunities of various kinds. The NASW Code of Ethics is, without question, the predominant social work ethical code in the United States. However, there are other codes that have merit (e.g., National Association of Black Social Workers, International Social Workers, Canadian Association of Social Workers, Federation of Clinical Social Workers, Code of Radical Social Workers). We believe that these other codes may contribute to students' education and enable them to recognize the value of different professional perspectives. Nonetheless, the implicit endorsement of the NASW Code establishes a clear and specific expectation for all social work students educated in accredited programs in the United States.

\section{Diversity}

Emerging societal changes will impact the way we conceive and shape social work practice in the next decade (2004-2014). We expect that in the years ahead, the process of devolution will continue on a global scale with repercussion at the individual and community levels. There are clear predictors of significant demographic changes in the USA based on the nature of work (Gurnstein, 1996), multiculturalism (Kivisto \& Rundblad, 2000), religion/spirituality (Porter, 2000), and the aging of the population (Greene, 2000). Advances in technology will bring greater connectivity among people and social agencies (Schoech, Cavalier \& Hoover, 1993; Queiro-Tajalli \& Campbell, 1999) as well as widening the gap between the "technology rich" and the "technology poor" (Tapscott, 1998). Clearly, these changes will expand the nature of diversity in previously unimagined ways.

Several foundation program objectives refer to the abilities social workers require in serving diverse populations. We believe that the phrase "integrate con- 
tent," as used in the passage "integrate content that promotes understanding, affirmation, and respect for people from diverse backgrounds," (CSWE, 2001, p. 9), suggests that BSW programs are expected to thoroughly address diversity content throughout the foundation curriculum. Similarly, the term "affirmation" is used in the new policy. We posit that "affirmation extends well beyond tolerance" to suggest an active, engaged search for the value and meaning of diversity among individuals, groups, and communities. This implies a commitment to practice that truly reflects competence in diversity even if it requires opposing mainstream professional practices.

If BSW programs design curriculums and implement learning experiences suggested by the diversity-related foundation objectives and content, we anticipate that graduates will be ethnically- and culturally-sensitive practitioners capable of enhancing human well-being in partnership with diverse clients.

\section{Populations-at-Risk and Social and Economic Justice}

Whereas diversity content helps students learn to acknowledge, celebrate, promote, and affirm diversity in BSW practice, the Populations-at-Risk and Social and Economic Justice content encourages students to learn and think critically about deeply ingrained mechanisms of oppression that adversely impact the lives of individuals, groups, and communities.

EPAS does not specifically identify which at-risk-groups should be addressed within the foundation curriculum. However, two foundation program objectives indicate that graduates must demonstrate the abilities to "practice without discrimination and with respect, knowledge, and skills related to clients' age, class, color, culture, disability, ethnicity, family structure, gender, marital status, national origin, race, religion, sex, and sexual orientation"(CSWE, 2001, p. 8), and to "understand the forms and mechanisms of oppression and discrimination and apply strategies of advocacy and social change that advance social and economic justice" (CSWE, 2001, p. 8). Among the purposes of the profession are to “... alleviate poverty, oppression, and other forms of social injustice” (p. 5) and “...pursue policies, services, and resources through advocacy and social or political actions that promote social and economic justice" (p. 5). Social work education is charged with the responsibility to prepare social workers who are able to engage in activities intended to achieve such professional purposes.

In generalist practice, we cannot target our focus of intervention on the individual without addressing those societal constraints that place diverse groups at risk. By the same token, we cannot address societal oppression without intervening to mitigate its impact at the interpersonal level.

The EPAS enables BSW programs to build upon lessons learned from earlier attempts to develop and deliver content in this area. Certainly, given the intricate interaction between economic and societal factors, greater emphasis on "economic justice" is needed. Indeed, the 2001 EPAS requires coverage of "distributive justice, human and civil rights, and the global interconnection of oppression" and “...prepare students to advocate for non-discriminatory social and economic systems" (CSWE, 2001, p. 10). In addition, the EPAS suggests that BSW programs include Human Behavior and the Social Environment content about “...empiri- 
cally based theories and knowledge that focus on the interactions between and among individuals, groups, societies, and economic systems" (p. 10).

We recognize a clear need to educate students about economic systems as entities that can deter or enhance individual and community growth. As educators, we look forward to helping students learn to assess the sources and ramifications of oppression within the interconnection of global systems and demonstrate competency in efforts to achieve distributive justice and human and civil rights, and to develop nondiscriminatory social and economic systems within a global perspective.

As we complete this manuscript, the horrendous attacks of September 11, 2001, and the subsequent retaliation by the United States, combined with fears of biological warfare are extremely painful reminders of the negative side of global interconnections in the $21^{\text {st }}$ century. At the same time, we experience the compassionate face of global interconnections in the form of solidarity, unity, and relief efforts. The unspeakable acts of violence and the expressions of compassion have revealed the worst and best of globalization. As Queiro-Tajalli and Campbell (2002) state, "These horrendous attacks will not abate, but may intensify given the apparent intolerance toward diversity and a seemingly ever-increasing lack of respect for human rights on a global scale." Perhaps, for the first time in our lives as educators, students, and practitioners, we must grapple with so many unanswered questions related to national and international social and economic justice. We hope to seize the opportunity of a new educational policy statement to transform our curriculums to encourage the preparation of competent practitioners in a world of contradictions, where forces of destruction are so closely interrelated with those of construction, goodwill, and resilience. We support Asamoah, Healy, and Mayadas (1997) in their call to abandon “...the conceptual separation of domestic and international content and move toward a curriculum with a truly global perspective" (p. 389) in order to prepare students for the realities of this millennium.

\section{Social Welfare Policy and Services}

EPAS highlights the integral relationship between policy and practice. The document emphasizes policy analysis from local to international levels as well as the explicit linkage of policy to social work practice. It makes clear that BSW programs must help students develop "policy practice skills" needed to participate actively in the policy development process in both organizational and political contexts.

This emphasis on policy practice and advocacy skills places policy squarely in the midst of the practice of social work, not as a separate foundation content in the curriculum. The challenge for BSW educators is how to make this linkage explicit for students.

\section{Social Work Practice}

The 2001 EPAS continues to emphasize generalist practice. Each BSW graduate is expected to demonstrate the ability to "apply the knowledge and skills of generalist social work practice with systems of all sizes" (p. 8). Furthermore, content about social work practice should focus on "strengths, capacities, and resources of client systems in relation to their broader environments" (p. 10), help students learn to 
develop, analyze, advocate, and provide "leadership for policies and services; and promoting social and economic justice" (CSWE, 2001, p. 10).

The educational policy appears to suggest that policy and practice content be more integrated, and that policy-related work is indeed part of social work practice. "Policy practice skills" seem fundamental to generalist social work practice. We anticipate that the integration of policy and practice will serve graduates well. It will equip practitioners with the knowledge and skills to provide leadership in developing policies and programs that are research-based, tailored to the circumstances of state and local contexts, and derived from their experience serving clients affected by social policies.

This content area also calls for a curriculum that includes empirically-based interventions to achieve client goals. We believe that this mandate will reinforce the orientation of best practices in social work. There is no doubt that empirically-based practice is of paramount importance in the $21^{\text {st }}$ century, yet, we are cognizant that as a profession we are continually challenged to agree as to what is an effective intervention and for whom it is effective.

The inclusion of the application of empirical and technological advances to practice is another important aspect of the foundation practice content. The context of contemporary social work practice is changing dramatically and will continue to do so in light of emerging knowledge and advances in technology. BSW students need to know about the risks and opportunities associated with technological innovations as well as legal and ethical factors associated with its application in practice. Access to services through agency-sponsored "chats" or "e-mail support groups" increase accessibility, particularly to clients who have typically been underserved, those in remote or rural areas, and those whose mobility challenges limit their ability to physically access agencies for services. Online counseling or teleconferencing expands the possibilities for reaching those who have been isolated. BSW social workers prepared for generalist practice also need to learn about the potential for "electronic community organizing" and the use of technology for advocacy purposes (FitzGerald \& McNutt, 1999; McNutt \& Boland, 1999; Queiro-Tajalli \& Campbell, 2002).

As we promote the promising aspects of technology in social work practice, we need to educate students in the ethical use of technology (Cwikel \& Cnaan, 1991) and in the obligation social workers have to advocate for access to technology for all people. Numerous writers (Pippa, 2001; Slater, 2000; Tapscott, 1998; Vernon \& Lynch, 1999) have warned us about the dangers of a "digital divide" in the information society, creating a gap that separates those with access to the Internet and those without (Slater, 2000). In the industrial economy we talked about an unequal distribution of resources creating a division between the "haves" and "the have-nots." In the information society we have to be vigilant not to allow society to become fragmented between "the knowers and know-nots" and the "doers and do-nots" based on access to technology and education.

\section{ACCREDITATION STANDARDS}

Educational accreditation standards establish a minimal level of expectation without either establishing or guaranteeing excellence. Some authors have point- 
ed out that at times, accreditation standards may impede curricular innovation (Markward \& Drolen, 1999), may not assure program effectiveness (Wellman, 2000), and may contribute to conflict and controversy among the social work professional and academic communities (Gibbs, 1995).

Despite its occasional disadvantages, accreditation is the vehicle social work education and educators have chosen to help define the profession, refine curriculum, and develop generations of practitioners. The question that must be addressed is what impact the EPAS will have on social work education in teaching, training, and socializing future practitioners.

\section{Budgetary Authority}

EPAS mandates the presence of "sufficient" resources in the area of support staff, other personnel, library resources, office and classroom space, and technology necessary to "achieve program goals and objectives" (p. 14). BSW programs will be challenged to document what is "sufficient" in order to achieve their mission. This is also related to the question of who owns the budget? While the 1994 Evaluative Standard clearly stated that "the program must have its own budget, as well as responsibility for budget development and administration" (CSWE, 1994, p. 82), the 2001 Accreditation Standard 3 is silent on this issue. The closest statement is Accreditation Standard 3.1.2, which reads, "The program has sufficient and stable financial supports that permit program planning and achievement of program goals and objectives. These include a budgetary allocation and procedures for budget development and administration" (CSWE, 2001, p. 14). It appears that budget planning and implementation need not be the prerogative of the social work faculty and administrators. We wonder about the implications of potentially reduced budgetary authority within BSW programs in an educational context of competing programs and diminishing resources.

\section{Non-discrimination and Human Diversity}

EPAS requires BSW programs to make "specific and continuous efforts to provide a learning context in which respect for all persons and understanding of diversity (including age, class, color, disability, ethnicity, family structure, gender, marital status, national origin, race, religion, sex, and sexual orientation) are practiced" (CSWE, 2001, p. 16). This standard appears to make clear that programs must adopt policies and practices that respect diversity and prohibit discrimination.

Although the legal rationale for less affirmative language may be understandable, many social work educators wonder about the nature of professional social work education in college and university contexts that do not support protection for vulnerable groups. The positions of certain religions on topics such as sexual orientation and status of women may make it difficult for some BSW programs to provide learning contexts that meet accreditation standards related to nondiscrimination and human diversity. We wonder how BSW programs of all kinds will respond to this mandate. Similarly, we wonder how accreditation site visitors and commissioners will evaluate programs on this standard. We anticipate considerable controversy in the years ahead. 


\section{Program Assessment and Continuous Improvement}

Program assessment is at the core of the accreditation process. Through assessment, programs demonstrate that they are accomplishing their mission and goals. As suggested by Palomba and Banta (1999a), assessment involves more than the purposeful collection of data. Assessment also includes the use of information to improve educational programs. The "ultimate emphasis of assessment is on programs rather than on individual students" (p. 5).

Program assessment has been difficult for many social work programs to implement. According to Baskind, Shank, and Ferraro (1999), "96\% ( $N=70)$ of all programs that were reviewed for reaffirmation for the period February 1998 through October 1999 were required to submit an interim report for this standard" (p. 103). Clearly, regular assessment is essential for the development and maintenance of quality social work education. EPAS requires programs to demonstrate that they have a conceptual plan for assessment, that they implement the plan, and that based on the analysis of the assessment data, that they make the necessary adjustments to the educational program. Indeed, this standard requires that programs "evaluate the outcome of each program objective..." (p. 17). Such a requirement represents an opportunity for faculty to collaborate on assessment processes that relate specifically to each program's unique goals and objectives. As suggested by Banta, Lambert, and Black (2001), it is unlikely that a single assessment tool will meet all the needs of all programs. Certainly, some instruments (e.g., the BEAP) will be useful across-the-board but programs will undoubtedly need to develop additional processes (e.g., portfolios, capstone products, comprehensive exams).

We hope that program assessment will be used to enhance students' learning and strengthen the quality of social work programs. We recognize that some programs may engage in assessment primarily to "satisfy" accreditation expectations. We also fear that program assessment results may be used for purposes other than quality improvement (e.g., personnel evaluation, funding decisions, or program elimination). If programs anticipate that negative findings constitute major risks to their survival or accreditation status, the processes of assessment may become superficial or irrelevant.

\section{Program Renewal}

Program renewal is closely related to assessment in the inclusion of relevant stakeholders in the process. Programs are required to have "ongoing exchanges with external constituencies that may include social work practitioners, social service recipients, advocacy groups, social service agencies, professional association, regulatory agencies, the academic community, and the community at large" (CSWE, 2001, p. 16). While each stakeholder may have different roles in assessment and program renewal, each is a precious resource to improve the quality of social work education.

Integral to the emphasis on program assessment and renewal is the encouragement for programmatic innovation and change. The 2001 EPAS permits "programs to use time-tested and new models of program design, implementation, and evaluation" and encourages "programs to respond to changing human, professional, and institutional needs" (p. 3). We welcome this opportunity to meet 
accreditation standards while changing and revising curriculums and learning experiences in our efforts to improve educational quality.

\section{CONCLUSIONS}

Social work is a diverse profession as reflected in its many practice modalities, varied ideologies, and wide range of fields of practice. Nonetheless, throughout the history of social work accreditation, educators have captured the essential elements of the profession and have integrated them into curriculum policy statements, including the recently approved EPAS. Based on the many faces of the profession, the demands on BSW education are many. However, this has been the case since 1974 when the Council on Social Work Education began to accredit undergraduate social work programs. Certainly, the new EPAS calls for more emphasis in certain areas, including technology, affirmation of diversity, empirically-based research and interventions, and attention to global systems. In the final analysis, the EPAS has retained the intent of the 1992 Curriculum Policy Statement program objectives. Nonetheless, we should not feel complacent about current curriculum designs and content but take the opportunity afforded by EPAS to bring changes in the curriculum that truly reflect our commitment to assist vulnerable populations and promote social and economic justice. Furthermore, through our assessment processes, we should determine the validity of what we teach and the praxis of how we teach.

\section{References}

Asamoah, Y., Healy, L. M., \& Mayadas, N. (1997). Ending the international-domestic dichotomy: New approaches to a global curriculum for the millennium. Journal of Social Work Education, 33(2), 389-401.

Banta, T. W., Lambert, J. L., \& Black, K. E. (2001). Collaboration counts: The importance of cooperative work in assessing outcomes in higher education. In M. E. Dal Pai Franco, \& M. Costa Morosini (Eds.), Redes Academicas e Producao do conhecimento em educacao superior. Brazil: National Institute of Educacional Research.

Baskind, F. R., Shank, B. W., \& Ferraro, E. (1999) Accountability for professional practice. Assessment in social work education. In C. A. Palomba, \& T. W. Banta (Eds.) (1999). Assessing student competence in accredited disciplines: Pioneering approaches to assessment in higher education (pp. 95-120). Sterling, VA: Stylus.

Congress, E. P. (1999). Social work values and ethics. Identifying and resolving professional dilemmas. Chicago, IL: Nelson-Hall Inc.

Council on Social Work Education. (2001). Educational policy and accreditation standards. Alexandria, VA: Author.

Council on Social Work Education. (1994). Handbook of accreditation standards and procedures. Alexandria, VA: Author.

Cwikel, J. G., \& Cnaan, R. A. (1991). Ethical dilemmas in applying second-wave information technology to social work practice. Social Work, 36(2), 114-120.

FitzGerald, E., \& McNutt, J. G. (1999). Electronic advocacy in policy practice: A framework for teaching technology based practice. Journal of Social Work Education, 35(3), 331-341.

Gibbs, P. (1995). Accreditation of BSW Programs. Journal of Social Work Education, 31, 4-17.

Gordon, W. (1965). Toward a social work frame of reference. Journal of Education in Social Work, 1, 19-26.

Greene, R. (2000). Social work with the aged and their families ( $2^{\text {nd }}$ ed.). New York: Aldine De Gruyter.

Gurnstein, P. (1996). Planning for telework and home based employment: Reconsidering the home/work separation. Journal of Planning Education and Research, 15(3), 212-224. 
Kivisto, P., \& Rundblad, G. (Eds.) (2000). Multiculturalism in the United States. Current issues, contemporary voices. Thousand Oaks, CA: Pine Forge Press.

Markward, M., \& Drolen, C. S. (1999). Do accreditation requirements deter curriculum innovation? Journal of Social Work Education, 35, 183-195.

McNutt, J. G., \& Boland, K. M. (1999). Electronic advocacy by non-profit organizations in social welfare policy. Non-profit and Voluntary Sector Quarterly, 28(4), 432-451.

National Association of Social Workers. (1999). Code of ethics. Washington, D.C.: Author.

Palomba, C. A., \& Banta, T. W. (1999a). Assessment essentials: Planning, implementing, and improving assessment in higher education. San Francisco, CA: Jossey-Bass Publishers.

Palomba, C. A., \& Banta, T. W. (Eds.) (1999b). Assessing student competence in accredited disciplines. Pioneering approaches to assessment in higher education. Sterling, Virginia: Stylus.

Pippa, N. (2001). Digital divide: Civic engagement, information poverty, and the Internet worldwide. Cambridge, NY: Cambridge University Press.

Porter, R. Y. (2000). Clinical issues and intervention with ethnic minority women. In J. F. Aponte, \& J. Wohl (Eds.), Psychological intervention and cultural diversity ( $2^{\text {nd }}$ ed.) (pp. 183-199). Needham Heights, MA: Allyn, \& Bacon.

Queiro-Tajalli, I, \& Campbell, C. (2002). Organizing women of color online. In S. Hick \& J. McNutt (Eds.), Social work advocacy and community organizing on the Internet, (pp. 113-127). Chicago:Lyceum.

Queiro-Tajalli, I., \& Campbell, C. (1999). Challenges of program directors and field instructors: Use of information technology in field instruction. Paper presented at the Annual Baccalaureate Program Directors Conference, St. Louis, Missouri, November 3-7, 1999.

Ritzer, G. (2000). The McDonaldization of society. Thousand Oaks, CA: Pine Forge Press.

Schoech, D., Cavalier, A., \& Hoover, B (1993). A model for integrating technology into a multi-agency community service delivery system. Assistive Technology, 5(1), 11-23.

Slater, D. (2000). Low-income grassroots organizations work to close the digital divide. Paper presented on COMM-ORG: The On-Line Conference on Community Organizing and Development. [On-line] http://comm-org.utoledo.edu/papers.htm.

Tapscott, D. (1999). Growing up digital. The rise of the net generation. New York, NY: McGraw-Hill.

Vernon, R., \& Lynch, D. (1999). Social work on the web: Tools for cyberpractice. The Indiana Social Worker, 17(6), 1-2.

Wellman, J. V. (2000, September 22). Accreditors have to see past learning outcomes. The Chronicle on Higher Education, p. B20.

\section{Author's Note:}

Address correspondence to: Irene Queiro-Tajalli, Indiana University School of Social Work, 902 West New York Street, Indianapolis, IN 46202-5156 USA, itka100@iupui.edu. 